\title{
CARRINHOS PARA CRIANÇA: TÓPICOS EM ERGONOMIA, USABILIDADE E ACESSIBILIDADE
}

\section{KID STROLLERS: ERGONOMICS, USABILITY AND ACCESSIBILITY TOPICS}

\author{
Walter Correia ${ }^{1}$, D.Sc. \\ wfmc10@gmail.com e https://orcid.org/0000-0002-6491-9783 \\ Weynner Santos ${ }^{1}$, M.Sc. \\ wkbs@,cin.ufpe.br e https://orcid.org/0000-0001-7420-8718 \\ Ruth Epsztejn², D.Sc. \\ repsztejn@inmetro.gov.br e https://orcid.org/0000-0002-0405-9566 \\ Luciana Carvalho ${ }^{2}$, M.Sc. \\ lacarvalho@inmetro.gov.br e https://orcid.org/0000-0003-3270-7927 \\ Karine Murad ${ }^{2}$, Bach. \\ kmurad@inmetro.gov.br e https://orcid.org/ 0000-0003-4126-980x \\ ${ }^{1}$ Laboratório de Concepção e Análise de Artefatos Inteligentes/CAC, UFPE, Recife, Brasil \\ ${ }^{2}$ Diretoria de Avaliação da Conformidade/Inmetro, Rio de Janeiro, Brasil
}

\begin{abstract}
ergonomia, design, experiência do usuário, carrinho para criança
A equipe do Inmetro realizou uma análise preliminar em um carrinho para criança devido a um relato de acidente registrado na sua Ouvidoria. Foram constatados que todos os requisitos de segurança e de registro do produto foram cumpridos e a avaliação de risco do produto obteve nível de risco grave. Foi então estabelecido o contato à equipe do Laboratório de Concepção e Análise de Artefatos Inteligentes - LaCA2I da Universidade Federal de Pernambuco UFPE para estudo técnico do problema e identificação de possível revisão de normas/regulamentos no que tange ao design. $\mathrm{O}$ estudo foi desenvolvido segundo abordagem dedutiva de pesquisa. $\mathrm{O}$ artigo apresenta diretrizes, guias, requisitos e apontamentos de design de produto, baseados no corpo de conhecimento da Experiência do Usuário, mais especificamente, nas disciplinas de Ergonomia, Usabilidade e Acessibilidade, complementadas por tópicos de estética e Design Emocional. Nos resultados, são demonstrados dados preliminares de sua aplicação num teste piloto desse conjunto de avaliações com o modelo problemático, sugestões de itens dos temas estudados para a norma ABNT NBR 14389:2010: Segurança de carrinhos para crianças.
\end{abstract}

ergonomics, design, user experience, kid stroller Inmetro team realized a preliminary analysis of a kid stroller because of an accident report registered in their ombudsman. It was noticed that all the safety and registering requirements of the product were fulfilled and yet, the product reproved obtaining a high risk grade. The team of LaCA'I (Laboratory of Concept and Analysis of Artefacts with Intelligence) from UFPE (Federal University of Pernambuco) was then contacted to perform a technical study of the problem, by identifying a possible review of the standards/regulations used for the strollers design. The study was built inside a deductive research approach. The paper presents guidelines, instructions, requirements and appointmens to the product design, based on the body of knowledge of User Experience, more specifically, the disciplines of Ergonomics, Usability and Accessibility, complemented by topics of Aesthetics and Emotional Design. The results demonstrate preliminary data and their applications on a pilot test of this evaluation group with the flaw product, suggesting itens from the studied themes to the ABNT NBR 14289:2010 standard: Safety of kid strollers. 


\section{Introdução}

Produtos infantis são amplamente usados para facilitar os cuidados com as crianças. Contudo, esse público possui tantas fragilidades físicas, que tais produtos requerem maior precaução que outros objetos (FERNANDES et al. 2011). Para ser considerado seguro, eles precisam se adequar a muitas normas e regulamentos publicados pelas respectivas instituições responsáveis. Essas instituições supervisionam a correta utilização de materiais, técnicas e processos, atendendo a seus pré-estabelecidos coeficientes de segurança.

No Brasil, a Associação Brasileira de Normas Técnicas - ABNT - é responsável pela elaboração das Normas Brasileiras (ABNT NBR), através de seus Comitês Brasileiros (ABNT/CB), Organismos de Normalização Setorial (ABNT/ONS) e Comissões de Estudo Especiais (ABNT/CEE) (ABNT, 2020) enquanto o Instituto Nacional de Metrologia, Qualidade e Tecnologia - Inmetro (INMETRO, 2020) regulamenta produtos nos aspectos de saúde, segurança, meio ambiente e práticas de comércio (Lei N ${ }^{\circ}$ 9.933/1999 (Brasil, 1999) e Lei 12.545/2011 (Brasil, 2011).As normas e regulamentos técnicos são desenvolvidos à medida que novos problemas são encontrados e novos produtos são confeccionados, sendo este trabalho, um esforço conjunto em prol da segurança dos usuários dos produtos. Muitas vezes, a ABNT elabora normas por demanda do Inmetro.

O Inmetro atua alinhado às políticas do Sistema Nacional de Metrologia, Normalização e Qualidade Industrial (Sinmetro) e às práticas internacionais. Em seu contexto, qualidade compreende o grau de atendimento (ou conformidade) de um produto, processo, serviço ou ainda um profissional a requisitos mínimos estabelecidos em normas ou regulamentos técnicos, ao menor custo possível para a sociedade (INMETRO, 2020a).

Neste artigo, é tratado um problema que foi identificado em um carrinho para bebês de fabricação nacional, marca A, modelo X, que apesar de aprovado nos ensaios de segurança previstos no regulamento publicado pelo Inmetro, durante o processo de avaliação da conformidade, houve reclamação por parte da mãe de uma criança, apontando uma possibilidade de brecha no regulamento vigente que tem como base a norma ABNT NBR 14389:2010 - Segurança de carrinhos para crianças (ABNT, 2010).

No problema relatado, a criança possivelmente machucou a cabeça mais de uma vez em duas quinas laterais presentes na parte interna do carrinho (Figura 1). Quando foi contatado, o fabricante respondeu que se tratava de uma característica do produto e não um defeito de fabricação, sendo o problema relatado na Ouvidoria do Inmetro, e posteriormente, também no SINMAC - Sistema Inmetro de Acidentes de Consumo (INMETRO, 2020c), que o encaminhou para apreciação na Divisão de Vigilância de Mercado Divig / Diretoria de Avaliação da Conformidade - Dconf.

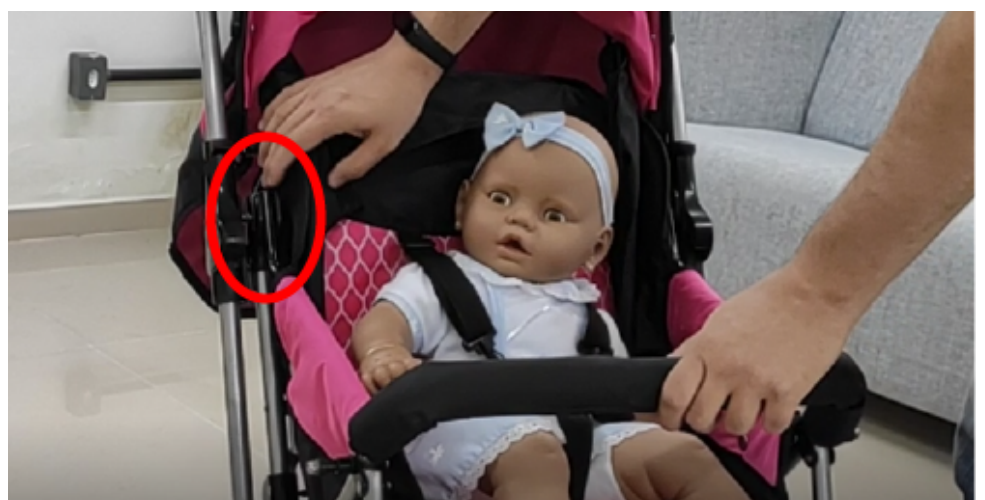

Figura 1. Componente causador do acidente reportado ao Inmetro. $\mathrm{O}$ acidente ocorreu num momento que a mão não estava olhando para a criança dentro do carrinho (produção dos autores). 
A equipe da Divig verificou que o produto estava regular em termos de certificação e de registro, conforme a Portaria Inmetro $n^{\circ}$ 315/2012 (INMETRO, 2020c) e Portaria Inmetro no 351/2012 (INMETRO, 2020b).

Como análise complementar, a equipe realizou avaliação de risco do produto de acordo com a orientação da rede RAPEX - Rapid Alert System for All Dangerous Consumer Products (em português, Sistema de Alerta Rápido para Todos os Produtos de Consumo Perigosos) (EUROPEAN COMMISSION, 2019), onde o produto obteve nível de risco S, atribuído como Risco Grave.

Considerando que produto faz parte do escopo de atuação do Inmetro, está em situação regular e o resultado da classificação de risco obtida, a equipe Divig decidiu entrar em contato com a equipe do Laboratório de Concepção e Análise de Artefatos Inteligentes - LaCA²I da Universidade Federal de Pernambuco/UFPE para a realização de um estudo técnico do problema e identificação de possível revisão de normas/regulamentos no que tange ao Design (GOMES FILHO, 2008). Vale destacar que o Laboratório $\mathrm{LaCA}^{2} \mathrm{I} / \mathrm{UFPE}$ se dedica ao estudo do design de artefatos inteligentes no qual são desenvolvidas atividades na área de ergonomia e usabilidade de produtos de consumo e de produtos inteligentes, incluindo a aplicação de metodologia de análise ergonômica de produtos. O presente estudo é uma das ações no âmbito de cooperação técnica e científica UFPE/Inmetro.

Neste contexto, foi necessária uma atualização que focasse na experiência do usuário, especialmente na interação humano-máquina, a qual recorre a princípios, informações e métodos de design que otimizam questões sobre bem-estar do usuário e performance do produto. Nesse sentido, qualquer tópico relacionado à estética toca nos fatores humanos, dentro de quatro subcampos que se complementam: ergonomia, usabilidade e acessibilidade.

Em Ergonomia, muitos componentes estão unidos através de questões relacionadas ao estímulo-reação e à afordância (KANNENGIESSER \& GERO, 2012). Ela se relaciona à experiência do usuário para avaliar a tangibilidade das interações, isso é, do artefato enquanto produto analógico, dotado de corpo real. Sua contraparte é a Usabilidade, uma disciplina que examina o quão fácil de usar é um sistema, sendo comumente aplicada ao estudo das interfaces (NIELSEN, 2012). A acessibilidade é definida pela ISO 924120 (ISO, 2006) como algo que visa permitir que o máximo de pessoas com limitações de qualquer natureza, possa ter a mesma qualidade de uso de um produto que pessoas plenas. Já a experiência do usuário, ou $u x$, abrange tudo relacionado à interação, ao contato e às sensações do usuário provocadas pelo produto, mesmo quando um usuário descreve este produto para outra pessoa (NORMAN \& NIELSEN, 2020).

\section{Metodologia}

A seguinte metodologia foi elaborada para facilitar a aquisição de dados dentro das quatro áreas investigadas, bem como adquirir informações específicas sobre os carrinhos para criança dentro de cada uma delas. A equipe utilizou uma abordagem dedutiva de pesquisa (MARCONI \& LAKATOS, 2017), seguindo algumas perguntas de pesquisa: que grupo de guias poderia servir como uma intersecção de diretrizes da ergonomia, da usabilidade e da acessibilidade para avaliar carrinhos para criança na norma ABNT NBR 14389:2010? Como esses campos contribuem para a experiência geral de uso? Quais métricas desses campos poderiam ser implementadas no corrente texto da norma e/ou em seu protocolo de avaliação?

Através de uma extensa revisão assistemática de literatura, a equipe reuniu dados importantes de artigos, livros e relatórios a fim de construir um protocolo inicial de avaliação, que pudesse modificar ou completar a atual versão da norma. Neste documento, foram projetadas tais recomendações. Após a realização de teste piloto com a equipe do $\mathrm{LaCA}^{2} \mathrm{I} / \mathrm{UFPE}$, o relatório final com os resultados foi enviado ao Inmetro para apreciação e possível encaminhamento ao fabricante do carrinho com falhas; e para que outros modelos, desta e de outras fabricantes, possam ser reavaliados. 
Os objetivos desta revisão atendiam a cada uma dessas perguntas, e objetivaram levantar considerações, requisitos e apontamentos dessas quatro disciplinas, enquanto se desenhava um teste piloto para sua aplicação. Dessa maneira, próximas pesquisas deverão detalhar ainda mais a atual versão. Além disso, para garantir a qualidade dos documentos, foram aceitos apenas aqueles que operam dentro de uma das quatro disciplinas, de fontes públicas ou privadas, e somente os que tratam de carrinhos para criança ou partes dele.

\section{Sobre a Norma ABNT NBR 14389:2010}

Elaborada na Comissão de Estudo Especial de Segurança de Carrinhos para Criança (ABNT/CEE-144), com o intuito de revisar e de substituir a norma NBR 14389:1999; a NBR 14389:2010 (ABNT, 2010) é baseada na EN 1888:2003 (BSI, 2003) e Emendas 1, 2 e 3 de 2005. Ela não abrange usos intensivos ou por usuários considerados limítrofes, isso é, fora do escopo normal de uso. Abordando requisitos de segurança e os ensaios necessários exclusivamente para validar carrinhos de transporte individual ou coletivo de crianças, ela tem ainda como influência recomendações das NBR NM 300, partes de 1 a 3 (ABNT, 2004); NBR ISO/IEC 17025 (ABNT, 2017); e NBR 14400 (ABNT, 2009).

Juntas, elas abrangem aspectos como segurança e qualidade de brinquedos e assentos de veículos rodoviários, especificamente os dispositivos/assentos para retenção de crianças. Na norma NBR 14389:2010 são apresentadas tipologias e definições de transportadores de crianças, podendo eles ser empurrados, carregados e/ou dirigidos; na forma de carrinhos, cestos ou berços; mono e multiuso. Na norma, atualmente são definidos, descritos e avaliados o assento, o cesto, o chassi e os demais componentes que possam ser acessados por uma criança, intencional ou acidentalmente.

Apenas algumas poucas regras interferem diretamente na experiência do usuário, sendo aquelas ligadas às dimensões e à segurança pela suavização de zonas de risco físico, como bordas pontiagudas e áreas expostas. Precisam ser consideradas então, questões sobre eficácia, eficiência, conforto (da criança e do condutor), aprendizibilidade, memorabilidade, facilidade de uso e sensação de segurança. Através de testes de manuseio, como o Teste de Erick (OLIVEIRA, 2010); da análise dos tipos de pegas por CUSHMAN \& ROSENBERG (1991); das heurísticas de usabilidade segundo NIELSEN (1994); e da adaptação de guias digitais de acessibilidade (SIDI, 2020; W3C, 2020); foi possível tornar a etapa de ensaios para a norma ABNT NBR 14389:2010 em algo complementado pelos Fatores Humanos.

\section{Ergonomia dos Carrinhos para Criança}

Quando um carrinho para criança é projetado, ele adquire a estética de um produto destinado aos pais, ainda que todas as considerações ergonômicas sirvam para melhor acomodar a criança no cesto. Os pais compram um carrinho que melhor se associa ao que eles enxergam como algo de boa qualidade, e nesse caso, a sensação de segurança e de conforto é muito mais importante para eles que a segurança e o conforto real que o artefato oferece. É para vencer este preconceito que os ergonomistas realizam estudos se perguntando: “com o que esses recém-nascidos interagem?” (ZUNJIC, 2017, p. 2, tradução dos autores).

Isso porque, devido à fragilidade destes usuários e a sensibilidade de seus parentes, é muito perigoso realizar testes de ergonomia com bebês. Por razões éticas, opta-se pelo uso de simulacros. No caso da Ergonomia, simulacros têm propósitos mecânicos e estéticos, com a mesma serventia de um protótipo (MARTIN \& HANINGTON, 2012). A questão dos carrinhos para criança é muito importante, porque eles serão o local onde a criança passará mais tempo depois do berço (ZUNJIC, 2017).

Também, acidentes com crianças em carrinhos são mais comuns do que se imagina. Estima-se que só na União Europeia, uma média de 5.900 crianças sofrem danos com carrinhos, requerendo atenção médica (SENGÖLGE \& VINCENTEN, 2013) e, em apenas um ano, 14.400 crianças menores que cinco anos 
receberam tratamento médico por causa de acidentes com carrinhos (U.S. CONSUMER PRODUCTS SAFETY COMMISSION, 1997). Existem seis cenários possíveis, no contexto do uso de carrinhos para criança, que afetam a carga sensível. Eles estão majoritariamente ligados ao sistema de restrição da criança no carrinho e na relação dessas "afordâncias de movimento" (LERNER et al., 2002), conforme descritos na Tabela 1.

\begin{tabular}{|l|l|l|}
\hline Cenário & Descrição & Idade comum \\
\hline Ficar de pé e cair & $\begin{array}{l}\text { Quando a criança consegue se levantar ou se ajoelhar no assento, e acaba caindo do } \\
\text { carrinho. }\end{array}$ & 8 a 15 meses. \\
\hline $\begin{array}{l}\text { Inclinar-se sobre a } \\
\text { lateral e cair }\end{array}$ & $\begin{array}{l}\text { Quando a criança se inclina sobre a lateral do carrinho, e acaba caindo, ficando } \\
\text { pendurada por cordões ou tombando o carrinho. }\end{array}$ & 7 a 15 meses. \\
\hline Inclinar-se e alcançar & $\begin{array}{l}\text { Quando a criança se inclina para os lados ou para a frente, alcançando as rodas ou } \\
\text { outros mecanismos do carrinho. }\end{array}$ & 7 a 24 meses. \\
\hline Avançar & $\begin{array}{l}\text { Quando a criança se inclina à frente do carro, saindo para fora ou ficando presa nas } \\
\text { restrições (cintos ou encaixe das pernas). }\end{array}$ & 6 a 9 meses. \\
\hline $\begin{array}{l}\text { Deslizar pela abertura } \\
\text { das pernas }\end{array}$ & $\begin{array}{l}\text { Quando a criança, ao remover uma das pernas de uma das aberturas, e colocá-la na } \\
\text { outra abertura junto à outra perna; desliza por ela, caindo ou ficando presa. }\end{array}$ & 4 a 9 meses. \\
\hline Deslizar na horizontal & $\begin{array}{l}\text { Quando o carrinho está com o assento deitado, e a criança desliza para frente ou para } \\
\text { trás, resultando em queda, tombo do carrinho ou oclusão facial. }\end{array}$ & 6 a 24 meses. \\
\hline
\end{tabular}

Tabela 1. Seis cenários de acidentes em carrinhos para criança quanto ao sistema de restrição (LERNER et al., 2002, p. 713; tradução dos autores).

Para evitar tais acidentes, alguns tópicos de segurança e conforto são essenciais à análise dos carrinhos, pois atuam para garantir a segurança e o bem-estar, tanto da criança quanto dos condutores, enquanto estiverem interagindo com o produto. Esses tópicos são elaborados e apresentados logo abaixo, na Tabela 2:

\section{Recomendações de Segurança}

Possuir cintos de segurança para manter a criança presa na posição desejada. Eles precisam ser resistentes, mas suas fivelas devem ser fáceis de abrir e fechar por um adulto em caso de emergências.

Um sistema de frenagem forte e imediato.

Os carrinhos não devem se dobrar ou se fechar com a criança dentro, apresentando uma trava para mantê-lo aberto.

O equilíbrio dos carrinhos não deve ser afetado por bagagens, que devem ser colocadas horizontalmente numa área própria para elas, em região embaixo do cesto ou atrás das rodas traseiras.

Não deve haver peças de plástico ou de metal que possam machucar a criança em áreas do carrinho acessíveis a ela, intencional ou acidentalmente.

\section{Recomendações de Conforto}

É preferível que a área interna do cesto seja plana (na superfície onde a criança é colocada) e que seja possível dobrá-la na forma de assento onde a criança fique sentada ereta.

A peça da pega deve permitir seu deslocamento seguro para trás e para a frente, para que a criança possa ver o rosto de seus pais.

A pega deve permitir o ajuste na vertical para evitar que o condutor curve o torso.

O carrinho deve possuir um dossel para que a criança seja protegida do sol, de luzes fortes e de chuvas, além de qualquer outra condição climática.

O carrinho deve possuir um descanso para os pés da criança, que deverá utilizá-lo à medida que cresce. 
Tabela 2. Recomendações básicas de segurança e conforto (RICE \& LUEDER, 2008; SENGÖLGE \& VINCENTEN, 2013; tradução e adaptação dos autores).

Outros apontamentos interessantes podem ser colhidos do trabalho de SEHAT \& NIRMAL (2017), que após uma extensa revisão histórica da evolução de carrinhos para criança e seus quesitos ergonômicos, prescreveram recomendações interessantes sobre o design desses produtos. Seu estudo aborda diversas patentes de carrinho para criança, de diversos modelos e origens. A partir dele, foram elaboradas as diretrizes listadas na Tabela 3.



Tabela 3. Recomendações ergonômicas para carrinhos para criança (SEHAT \& NIRMAL, 2017, p. 41-53; tradução e adaptação dos autores).

Outros direcionamentos podem ser consultados nas obras de autores consagrados como CUSHMAN \& ROSENBERG (1991). Algumas de suas recomendações definem valores para peso e dimensões de alguns componentes comuns a diversos produtos, como tipos e variações de pegas (Figura 2). 

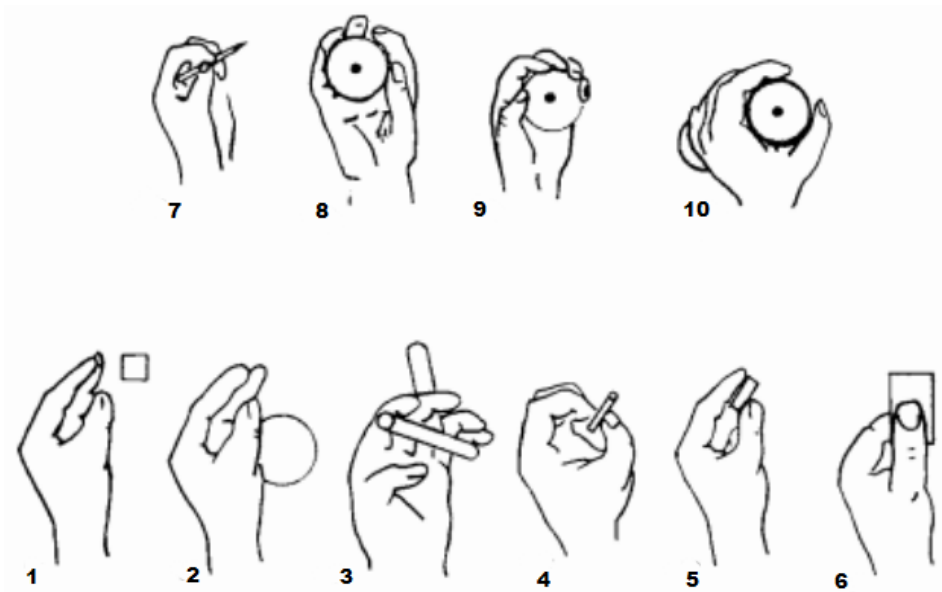

Figura 2. Diferentes tipos de pega para produtos manuais (KROEMER, 1986 apud CUSHMAN \& ROSENBERG, 1991; adaptação dos autores).

Em carrinhos para criança, o tipo de pega mais comum e mais recomendada é a de número 10, chamada pega de força, pois é a que mais oferece cobertura da mão sobre a estrutura e mais resistência no fechamento completo da palma. Este tipo de pega é classificado como preênsil. Diretrizes para a pega foram elaboradas e podem ser acessadas na Tabela 4, que segue:

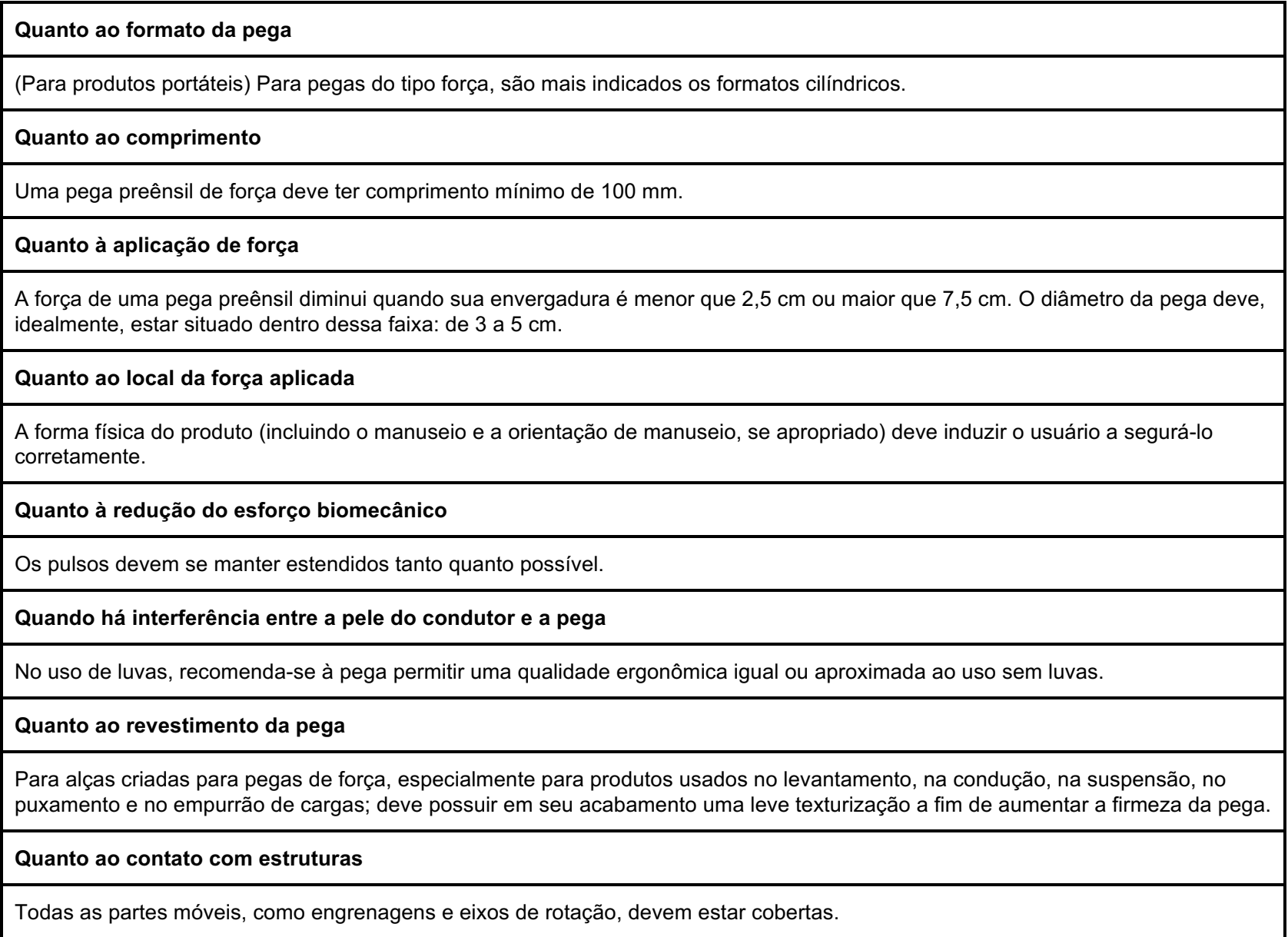

Tabela 4. Algumas diretrizes ergonômicas para pegas (portáteis móveis e transportáveis e. g. furadeiras) (CUSHMAN \& ROSENBERG, 1991; tradução de Marcelo M. Soares; adaptação dos autores). 
Diante de todas essas recomendações e diretrizes, apenas aquelas mais adequadas à atual carência de itens não abrangidos na avaliação do Inmetro de carrinhos para criança serão selecionadas para compor o protocolo de testes. Da mesma forma que será feito nos quesitos de usabilidade, de acessibilidade e de experiência do usuário dos tópicos seguintes. A revisão, então, configura um conjunto inicial de avaliações a serem executadas e testadas no modelo de carrinho que ocasionou acidente em uma criança.

\section{Usabilidade e Acessibilidade das Partes de um Carrinho}

Ergonomia e Usabilidade são duas disciplinas que fazem parte de um mesmo princípio: enquanto a primeira nasceu para melhorar a qualidade de produtos reais (interação humano-máquina), a segunda, como uma consequência direta da primeira, visava os produtos digitais (interação humano-computador). Apesar disso, quase todo profissional ergonomista tratará da usabilidade de produtos em algum momento, bem como os profissionais de usabilidade farão uso de conceitos da ergonomia em suas heurísticas (NIELSEN, 1993).

A questão é que a Ergonomia trata de uma espécie de corporalidade do artefato e sua relação com os indivíduos, enquanto a usabilidade trata do estudo da comunicação e do acesso a ela num produto, através de sua interface. Por comparação, poderia ser dito que: a ergonomia trata do corpo real; a experiência do usuário, do corpo semiótico; e a usabilidade, do corpo mídia. A acessibilidade seria a facilidade com que o usuário se conecta a esses corpos, ou seja, o corpo social.

No trato da Usabilidade, é importante entender quais as principais forças que atuam na sua administração quando avaliada num artefato, ainda mais neste projeto, que tratará de um objeto tridimensional. O fato é que, mesmo um produto físico sem qualquer botão ou display, ele ainda possui uma interface: uma superfície comunicativa que se representa pelas cores, pelos textos, pelas formas presentes em cada parte do carrinho. Para NIELSEN (2012), existem cinco componentes básicos de qualidade a serem considerados para examinar a usabilidade de uma interface (Tabela 5):

\begin{tabular}{|l|l|}
\hline Aprendizibilidade & $\begin{array}{l}\text { O quão fácil é para os usuários completarem tarefas básicas pela primeira vez quando se deparam com o } \\
\text { artefato? }\end{array}$ \\
\hline Eficiência & Após assimilarem o design, o quão rápido executam estas tarefas? \\
\hline Memorabilidade & $\begin{array}{l}\text { Quando os usuários retornam à tarefa após um período sem realizá-la, o quão rápido eles retomam a } \\
\text { proficiência? }\end{array}$ \\
\hline Erros & $\begin{array}{l}\text { Quantos erros os usuários cometem, qual a severidade desses erros e o quão facilmente eles conseguem } \\
\text { se recuperar desses erros? }\end{array}$ \\
\hline Satisfação & O quão prazerosa é a atividade de uso do artefato? \\
\hline
\end{tabular}

Tabela 5. Cincos componentes da usabilidade de uma interface (NIELSEN, 2012; tradução dos autores).

Outros pontos importantes, ainda, são adicionados às considerações da disciplina, como a questão da utilidade de um produto: ora, um artefato só é usável se corresponde às necessidades de seu usuário. Não existe objeto fácil de usar, se não se sabe para que serve (NIELSEN, 2012). Finalmente, a usabilidade, mais até que a ergonomia, é uma disciplina heurística, pois assume como verdade um conjunto de dados recorrentes entre usuários.

Neste estudo, optou-se por trabalhar numa adaptação dessas heurísticas para o estudo das qualidades de uso do carrinho, já que ainda não há nenhum estudo de usabilidade diretamente executado nesse tipo de produto, exceto aqueles internos aos estudos de ergonomia já consultados e aqui aplicados. As dez heurísticas de NIELSEN (1994) são até hoje o conjunto de conhecimentos mais utilizados para a análise de interfaces, e foram adaptadas ao contexto da Norma ABNT 14389:2010 (Tabela 6). 


\begin{tabular}{|c|c|}
\hline Heurística & Descrição \\
\hline $\begin{array}{l}\text { Visibilidade de status } \\
\text { do sistema }\end{array}$ & $\begin{array}{l}\text { O carrinho deve manter o usuário sempre informado sobre o que está acontecendo, através do feedback } \\
\text { apropriado e num tempo razoável. }\end{array}$ \\
\hline $\begin{array}{l}\text { Correspondência } \\
\text { entre o sistema e o } \\
\text { mundo real }\end{array}$ & $\begin{array}{l}\text { O carrinho precisa ser coerente à linguagem do usuário, com palavras, frases e conceitos familiares a ele, } \\
\text { em vez de termos orientados ao produto. Siga convenções do mundo real, fazendo a informação aparecer } \\
\text { em ordem lógica. }\end{array}$ \\
\hline $\begin{array}{l}\text { Liberdade e controle } \\
\text { do usuário }\end{array}$ & $\begin{array}{l}\text { Usuários frequentemente escolhem funções do produto por engano, e por isso, precisam de "saídas de } \\
\text { emergência" evidentes, que os ajude a voltar ao normal sem informações muito extensas sobre como fazer. }\end{array}$ \\
\hline $\begin{array}{l}\text { Consistência e } \\
\text { normas }\end{array}$ & $\begin{array}{l}\text { Usuários não devem ter que se perguntar que palavras, situações ou expressões diferentes querem dizer a } \\
\text { mesma coisa. Siga as convenções industriais. }\end{array}$ \\
\hline Prevenção de erros & $\begin{array}{l}\text { Melhor que mensagens de erro, é um design cuidadoso, que prevê e impede um problema antes que } \\
\text { aconteça. É importante eliminar as condições que levam ao erro ou oferecer confirmações antes de permitir } \\
\text { a execução de ações, através de mecanismos adicionais. }\end{array}$ \\
\hline $\begin{array}{l}\text { Reconhecer é } \\
\text { melhor que lembrar }\end{array}$ & $\begin{array}{l}\text { Minimize a carga de memória do usuário ao deixar os objetos, ações e opções visíveis. Usuários não devem } \\
\text { ter que lembrar de informações de um momento específico de uso para conseguir usar o produto num outro } \\
\text { momento. As instruções também devem estar claras e facilmente recuperáveis, quando preciso. }\end{array}$ \\
\hline $\begin{array}{l}\text { Flexibilidade e } \\
\text { eficiência de uso }\end{array}$ & $\begin{array}{l}\text { Mecanismos de aceleração, isso é, que aumentam a eficiência das tarefas; devem ser empregados para } \\
\text { facilitar o uso por usuários experientes, ao passo que não devem impedir ou dificultar o uso por usuários } \\
\text { amadores. }\end{array}$ \\
\hline $\begin{array}{l}\text { Estética e design } \\
\text { minimalista }\end{array}$ & $\begin{array}{l}\text { O carrinho não deve conter partes ou informações desnecessárias. Qualquer unidade extra de informação } \\
\text { irrelevante compete com outra unidade que seria mais útil, mascarando sua relevância. }\end{array}$ \\
\hline $\begin{array}{l}\text { Auxilie os usuários a } \\
\text { reconhecer, } \\
\text { diagnosticar e se } \\
\text { recuperar de erros }\end{array}$ & $\begin{array}{l}\text { Mensagens e alertas de erro devem ser comunicados em linguagem simples, sem códigos, indicando } \\
\text { precisamente o problema e uma possível solução. }\end{array}$ \\
\hline $\begin{array}{l}\text { Ajuda e } \\
\text { documentação }\end{array}$ & $\begin{array}{l}\text { O ideal é um produto sem documentação de ajuda, que por si só consiga ensinar a usar e ajudar durante o } \\
\text { uso. Mas por precaução, é importante fornecer algum tipo de documentação de ajuda, para o caso do } \\
\text { usuário precisar. Ela precisa ser de fácil acesso, direta e de rápida compreensão. }\end{array}$ \\
\hline
\end{tabular}

Tabela 6. Dez heurísticas de usabilidade para o design de um carrinho para criança (NIELSEN, 1994; tradução dos autores).

Antes mesmo de se começar qualquer novo design, é importante já considerar os tópicos de usabilidade em testes com o antigo design (NIELSEN, 2012), para evitar que as mudanças sejam puramente visuais. A acessibilidade é definida pela ISO/IEC Guide 71 (ISO, 2001) como o conjunto dos atributos que garantem o acesso a um artefato por pessoas com limitações, sejam estas quais forem (ISO, 2006; 2008). Apesar disso, a acessibilidade não se trata simplesmente de dar qualidade equivalente de uso a pessoas com deficiência, mas ela começa muito antes, num ponto de intersecção da inclusão social com a ciência e com a tecnologia.

É sobre garantir o acesso a um produto, sistema ou ambiente, ao maior número possível de pessoas, independentemente de sua origem, etnia, cultura, classe social ou limitações biológicas (ISO, 2001). No caso de estudos voltados aos carrinhos para criança, são menos ainda aqueles que oferecem tópicos e requisitos voltados aos condutores. Aqui, o foco é a acessibilidade dos recursos de ergonomia e de usabilidade para os condutores, que por vezes têm necessidades especiais ou mesmo variações antropométricas relevantes.

Para tal, optou-se por adaptar os requisitos de sistemas de acessibilidade digital (SIDI, 2020; W3C, 2020), os quais são conjuntos de conhecimentos testados e já validados que funcionam como apontamentos do que melhora a acessibilidade de uma interface digital. Eles são muito semelhantes aos sistemas de design propriamente ditos (PERNICE, 2018), que trazem bibliotecas de conteúdo e de componentes já validados em experiências anteriores de uma instituição. Nesse estudo, foram extraídos apontamentos de acessibilidade do Web Content Accessibility Guidelines (em português, Diretrizes de Acessibilidade para Conteúdo Web), ou 
WCAG, versão 2.1 (W3C, 2020) e do Guia para o desenvolvimento de Aplicações Móveis Acessíveis, ou GuAMA (SIDI, 2020). A Tabela 7 a seguir apresenta essas guias e esses requisitos suplementares da acessibilidade, adaptadas ao contexto do carrinho para criança.

\begin{tabular}{|l|l|}
\hline \multirow{3}{*}{ Fonte } & Requisito/Guia \\
\hline \multirow{5}{*}{} & R02. A pega deve ser entendida independentemente das cores e texturas. \\
\cline { 2 - 3 } & R03. A pega deve ser facilmente identificada, através de cores de alto contraste em relação ao resto do produto. \\
\cline { 2 - 3 } & R06. O produto deve usar linguagem adequada ao contexto do usuário. \\
\cline { 2 - 3 } & R22. Textos devem ser curtos e concisos, sempre que possível. \\
\cline { 2 - 3 } & R23. As partes do produto devem seguir a mesma identidade visual e manter o padrão de layout. \\
\cline { 2 - 3 } & R24. A localização dos componentes deve seguir padrões amplamente utilizados. \\
\cline { 2 - 3 } & R25. Informações textuais devem seguir o mesmo padrão. \\
\cline { 2 - 3 } & R27. O produto deve oferecer recursos que reduzam o esforço do usuário. \\
\cline { 2 - 3 } & R42. O produto deve disponibilizar opções de ajuda referente ao seu uso e às suas funcionalidades. \\
\hline WCAG 2.1 & Guia 1.1. Providencie alternativas de condução. \\
\cline { 2 - 3 } & Guia 2.5, Critério de Sucesso 2.5.6 - Permita o uso de mecanismos adicionais à pega para melhor condução. \\
\hline
\end{tabular}

Tabela 7. Requisitos do GuAMA e guias do WCAG 2.1 para carrinhos para criança (SIDI, 2020; W3C, 2020; tradução e adaptação dos autores).

Apesar dos guias serem para o contexto digital, a acessibilidade começou no meio real, principalmente no estudo do ambiente construído, migrou para o design de produto e depois, para o digital. Adaptar os guias é um retorno à essência da acessibilidade. É importante salientar que, muitos desses requisitos e guias trazem as mesmas cobranças de tópicos, diretrizes e recomendações de ergonomia e de usabilidade e, muitas vezes, as formas de aferi-los também são idênticas. Mas há uma grande diferença entre eles que impacta fortemente nos resultados: seus objetivos.

Enquanto uma diretriz de usabilidade que trata de cor enquanto unidade de informação está preocupada se aquela cor está condizente com as normas e com o contexto de uso em que se aplica (NIELSEN, 1994), isso é, se ela segue um padrão conhecido pela maioria das pessoas e se gera eficiência; a mesma tratativa de cor, em acessibilidade, busca entender se aquela cor consegue ser percebida tanto por um usuário pleno quanto por um daltônico (SIDI, 2020), ou se aquela cor é chamativa o suficiente caso seja aplicada num mecanismo de segurança do carrinho. Isso significa dizer que todo esse conjunto de testes, aliado aos demais, abrange um primeiro escopo de questões amplas, quanto às qualidades da forma e das funcionalidades do carrinho.

\section{Diretrizes e Resultados do Teste Piloto}

Podemos entender que a análise de ux foca na observação da relação do produto com o usuário final, na gestão de suas expectativas e na coleta de seus sinais que apontem níveis de insatisfação, dúvidas e problemas que reduzam a qualidade da experiência. Como os testes do Inmetro não focam na satisfação do usuário quanto a aspectos culturais e do consumo, a ux se limita aqui às questões mais tangíveis, como tópicos de estética e possíveis consequências emocionais da interação com usuários. 
O quanto antes as análises de ux precedem as de ergonomia e de usabilidade, mais rápida a aceitação do usuário quanto à versão comercial de um produto, o que também implica maior qualidade inerente ao artefato. Contudo, estas análises são realizadas pelo desenvolvedor do produto: seu objetivo não é o mesmo das instituições de regulamentação. Fabricantes focam em sucesso de vendas, enquanto instituições como a ABNT e o Inmetro precisam concentrar seus esforços em regular e verificar índices de segurança.

Isso significa que, os testes de experiência do usuário contemplam também todos os demais, visto que ergonomia, usabilidade e acessibilidade já estão inseridas no contexto de ux. Segue na Tabela 8 uma lista com algumas das trinta e nove diretrizes construídas e revisadas após teste-piloto com especialistas, classificadas de acordo com a parte do carrinho a ser avaliada ou com um campo específico de averiguação. Cada uma delas evoluiu a partir do agrupamento de recomendações, requisitos e guias dos quatro campos abordados, e podem sofrer futuras reorganizações.

\begin{tabular}{|l}
\hline Diretrizes para a pega \\
\hline A alça deve permitir uma pega do tipo força, para que a mão intuitivamente se projete sobre ela em forma de gancho. \\
\hline $\begin{array}{l}\text { O fechamento das mãos sobre o cilindro deve permitir o completo arqueamento dos dedos, com fechamento da mão pelo toque do } \\
\text { indicador com o polegar. }\end{array}$ \\
\hline A pega deve ter diâmetro entre 3 e $5 \mathrm{~cm}$. \\
\hline $\begin{array}{l}\text { É preferível um revestimento em material antideslizante e esponjoso para a alça, a fim de garantir um manuseio seguro, mesmo } \\
\text { com luvas. }\end{array}$ \\
\hline Diretrizes para a montagem (total dos componentes) \\
\hline $\begin{array}{l}\text { Peças pequenas, quinas, bordas, protuberâncias, botões, cordões e outros adereços estão proibidos em áreas internas ao cesto, } \\
\text { locais acessados pela criança ou na área da pega. }\end{array}$
\end{tabular}

Áreas vazadas não devem permitir a passagem de nenhum órgão da criança, como dedos, mãos e pés, exceto a área de entrada das pernas.

Travas e mecanismos devem ser inacessíveis à criança, e o carrinho deve permitir uma rápida transição de modalidade de uso (entre cadeira e berço ou vice-versa).

\section{Diretrizes para o cesto}

Espumas do assento não devem ser maleáveis ao ponto de permitir o afundamento da criança na superfície.

A quantidade e a posição dos cintos devem ser adequadas: cada arreio impedindo o movimento de um membro mais o tórax, havendo no máximo cinco arreios, para que o conforto não seja prejudicado.

O cesto deve possuir um dossel retrátil para que o bebê seja protegido do sol, da luz e da chuva.

\section{Diretrizes para o chassi}

O chassi não deve, sob qualquer hipótese, invadir a área útil do cesto ou interferir na alça, exceto quando a alça é parte ou prolongamento do próprio chassi.

O chassi deve ser alto o suficiente para que o cesto não fique próximo ao chão, e os braços do carrinho devem ser longos ou inclinados o suficiente para que haja espaço entre o carrinho e o condutor.

Bagageiros devem estar presentes sob o cesto ou atrás das rodas traseiras, sem impedir a condução do carrinho ou o rolamento dessas rodas. Deve haver uma área de apoio para os pés da criança e os pneus podem ter material ou mecanismos absorvedores de impacto.

Diretrizes para a interface de comunicação

As 10 heurísticas de Nielsen adaptadas ao contexto dos carrinhos. 


\begin{tabular}{|l|}
\hline Diretrizes para mais acessibilidade \\
\hline Textos devem ser curtos e concisos, sempre que possível. \\
\hline Componentes e textos devem ser padronizados e possuir a mesma identidade visual. \\
\hline $\begin{array}{l}\text { O carrinho deve oferecer recursos, opções e/ou instruções para reduzir o esforço do usuário e facilitar a aquisição de informações } \\
\text { de uso. }\end{array}$
\end{tabular}

Tabela 8. Diretrizes de qualidade revisadas após o teste piloto (CUSHMAN \& ROSENBERG, 1991; LERNER et al., 2002; NIELSEN, 2012; SEHAT \& NIRMAL, 2017; SIDI, 2020; W3C, 2020; tradução e adaptação dos autores).

Outros resultados relevantes da aplicação do piloto trouxeram considerações diretas ao modelo de carrinho avaliado, além de práticas que podem ou não ser implementadas durante os testes com outros modelos a serem futuramente avaliados pelo Inmetro. Sugere-se como etapa a seguir do presente estudo a validação pelos usuários dos tópicos ergonômicos, de usabilidade e de acessibilidade ao modelo avaliado e de outros de carrinho para criança.

\subsection{Quanto ao tempo de aprendizagem}

Algumas instruções do carrinho, além de estarem em locais de difícil acesso, não correspondem aos mecanismos a que se referem, podendo gerar confusão em alguns usuários. Por exemplo, indicar o peso máximo suportado pelo carrinho numa etiqueta no bagageiro pode induzir o usuário a pensar que aquela informação se refere apenas ao bagageiro. Também, o logo do produto se repete em várias áreas do chassi, $\mathrm{e}$ há pouco feedback sonoro para o uso de mecanismos.

\subsection{Quanto ao desempenho}

Como já mencionado, as protuberâncias internas ao cesto são o motivo do acidente reportado. Ademais, o local de cruzamento no chassi entre a estrutura que suporta o cesto e a que suporta a pega oferece risco de esmagamento às mãos de crianças maiores. Os freios do carrinho são fracos e facilmente desativados, há má hierarquização de cores e a estrutura geral do produto é demasiadamente leve. Esses fatores comprometem o desempenho do produto e a segurança de ambos condutores e bebês.

\subsection{Quanto à taxa de erros do usuário}

As falhas estruturais de desempenho bem como o design das travas, que não é intuitivo o suficiente, fazem com que o usuário cometa mais erros até aprender a manusear os mecanismos corretamente. Nem todas as travas são fáceis de acionar, e por isso, precisam de instruções simples em seu corpo ou próximas a elas. O redesign das travas é recomendado.

\subsection{Quanto à sedimentação do conhecimento pela experiência}

Além do carrinho não ter sido projetado para uma ampla variedade de usuários, do ponto de vista antropométrico, o conjunto de erros torna a curva de aprendizagem mais lenta, sedimentada a usuários mais experientes com o sistema, mesmo que o carrinho também se permita ser usado por amadores.

\subsection{Quanto à satisfação subjetiva}

Além da estética negativamente popular, isso é, quando um produto mais acessível financeiramente aparenta ter má ou baixa qualidade; o carrinho é pouco robusto, suas espumas e borrachas são finas (Figura 3) e partes de seu tecido são muito chamativas, o que pode levar a associações indesejadas por parte do usuário comprador. 


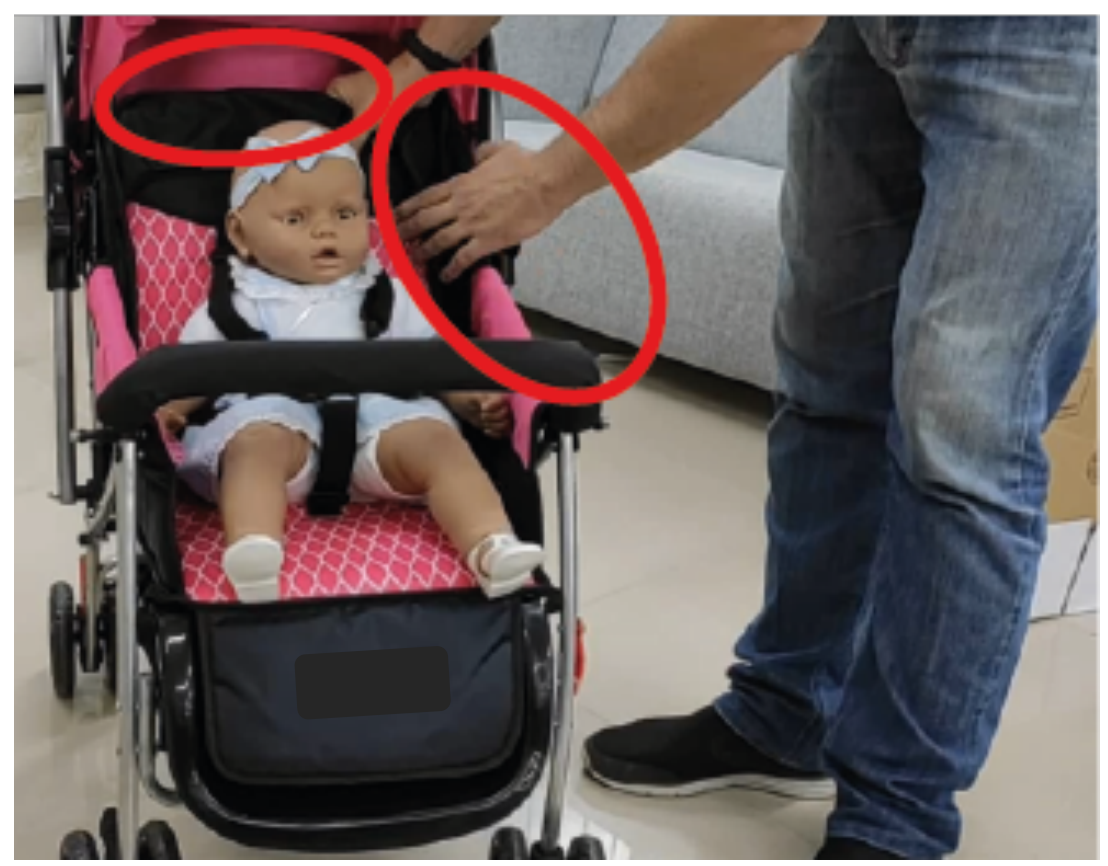

Figura 3. Espumas de proteção na região da cabeça e dos braços é muito fina. Mesmo com as quinas revestidas pela espuma, ainda é possível a criança se ferir (produção dos autores).

Outro resultado importante foi uma simulação feita a partir do Teste de Erick (OLIVEIRA, 2010), quando foi possível raciocinar acerca das áreas da palma da mão e dos dedos que são mais afetadas pela pega de força, isso é, quando a mão se fecha em forma de arco num cilindro. O teste consiste na aplicação de uma substância corante ou revestimento com massa deformável na área correspondente à pega. Após a total cobertura da área útil, o usuário segura a alça simulando o uso real do produto (Figura 4). A tinta deixará impressões na mão do usuário, apenas na região que realmente entrou em contato com a pele, sugerindo como uma nova pega poderia ser projetada a fim de respeitar o encaixe ideal das mãos. Tais marcas podem ser escaneadas ou fotografadas para as análises posteriores.

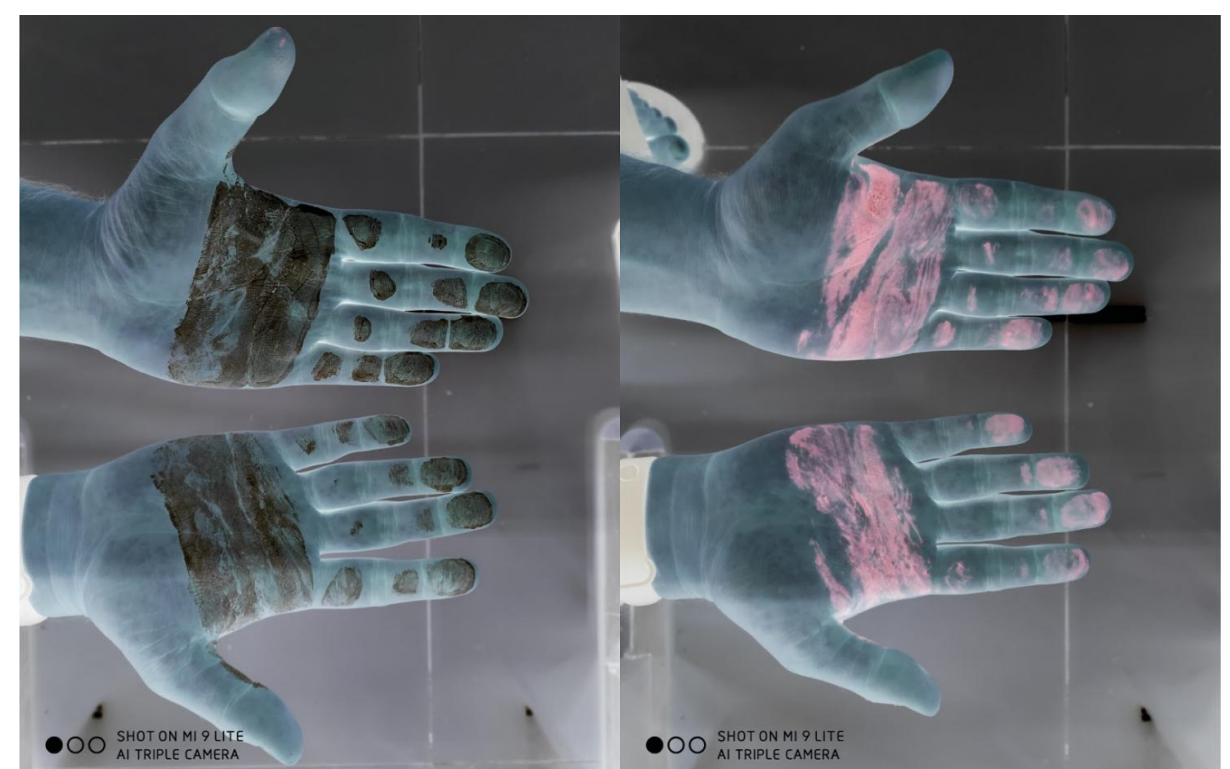

Figura 4. Filtro negativo para destacar zonas de influência da pega no carrinho para criança (produção dos autores). 
É importante salientar que um único teste não é o suficiente para aferir mudanças concretas, visto que a variação antropométrica entre usuários é importante para se alcançar um resultado médio entre os diversos perfis. Nesses resultados preliminares, percebe-se que há uma leve diferença no raio de alcance da mão entre as duas imagens, sendo que na primeira (da esquerda, o carrinho com o simulacro), o contato é ligeiramente mais amplo, pois quanto maior o peso total do produto, mais esforço é exercido na palma. O esforço aumenta a dilatação da pele, e consequentemente, a firmeza na pega. Ainda assim, há muita tensão na região central e superior da palma, além de pressão em todos os dedos, inclusive na lateral do polegar.

\section{Sugestões para a Norma ABNT NBR 14389:2010}

Para facilitar a inserção da análise da Experiência do Usuário nos carrinhos para criança, foram elencadas sugestões de modificação e inclusão para atualizar a norma vigente, fazendo apontamentos que permitissem que os problemas apresentados no relato fossem passíveis de prevenção, detecção, avaliação e correção. Algumas das principais sugestões estão listadas na Tabela 9, que segue:

\begin{tabular}{|c|c|c|}
\hline Seção tratada & Sugestões & Justificativa \\
\hline $\begin{array}{l}3 \text { Termos e } \\
\text { definições }\end{array}$ & $\begin{array}{l}\text { Incluir item: } \\
\text { 3.22 Condutor - Adulto responsável } \\
\text { pelo cuidado do bebê, controlando e } \\
\text { direcionando o carrinho }\end{array}$ & $\begin{array}{l}\text { Deve ser considerada a existência do condutor como elemento } \\
\text { de interação no produto, já que suas decisões e ações } \\
\text { interferem na segurança da carga preciosa. }\end{array}$ \\
\hline $\begin{array}{l}4.2 \text { Sequência de } \\
\text { Ensaios }\end{array}$ & $\begin{array}{l}\text { Incluir: } \\
2.4 \text { Acesso de compartimentos } \\
4.5 \text { Manejo do carrinho }\end{array}$ & $\begin{array}{l}\text { Verificar se durante o uso com o carrinho em posições } \\
\text { variadas, o acesso aos controles e aos compartimentos não } \\
\text { estão comprometidos. Verificar se há dificuldade de manejo da } \\
\text { alça. }\end{array}$ \\
\hline $\begin{array}{l}4.5 .2 \text { Massas de } \\
\text { ensaio }\end{array}$ & $\begin{array}{l}\text { Modificar: } \\
\text { 4.5.2.5 Massa de ensaio D, 4.5.2.6 } \\
\text { Massa de ensaio DO por Simulacro de } \\
\text { bebê que possua partes sensíveis } \\
\text { como ouvidos, olhos e boca passíveis } \\
\text { de verificação posterior de danos que } \\
\text { apontem riscos em caso de impacto }\end{array}$ & $\begin{array}{l}\text { Compreender o comportamento do produto diante de } \\
\text { situações de risco requer que a simulação seja o mais próximo } \\
\text { da condição real. Um protótipo que simule todas as partes de } \\
\text { um bebê, sua pele e seus movimentos, pode trazer resultados } \\
\text { mais precisos. No mínimo, o formato deve ser comparável ao } \\
\text { real. }\end{array}$ \\
\hline 5 Materiais & $\begin{array}{l}\text { Incluir tópico: } \\
5.4 \text { Biocompatibilidade }\end{array}$ & $\begin{array}{l}\text { Analisar as interações do produto no contato com a pele, tanto } \\
\text { do bebê quanto do condutor. É importante o uso de materiais } \\
\text { hipoalergênicos e verificar alterações de formato geradas por } \\
\text { desgaste e contato. }\end{array}$ \\
\hline $\begin{array}{l}5.4 \\
\text { Biocompatibilidade }\end{array}$ & $\begin{array}{l}\text { Incluir: } \\
\text { Análise de dureza de tiras e elementos } \\
\text { de segurança do bebê }\end{array}$ & $\begin{array}{l}\text { A pele sensível do bebê pode sofrer com o atrito no cinto e } \\
\text { com outros elementos de segurança. Mesmo sendo resultado } \\
\text { de movimentos involuntários, esse risco deve ser considerado. }\end{array}$ \\
\hline $\begin{array}{l}\text { 6.1.2.4.1 } \\
\text { Equipamento de } \\
\text { ensaio }\end{array}$ & $\begin{array}{l}\text { Modificar: } \\
\text { Sonda para tronco pequeno e sonda } \\
\text { para cabeça grande para simulacro de } \\
\text { bebê }\end{array}$ & $\begin{array}{l}\text { Sondas rígidas e com variáveis divergentes da situação real } \\
\text { podem trazer resultados imprecisos, principalmente em } \\
\text { ensaios que visam simular situações reais. As sondas atuais } \\
\text { não consideram a maleabilidade dos corpos. }\end{array}$ \\
\hline $\begin{array}{l}\text { 6.1.3 Bordas, pontas } \\
\text { e cantos }\end{array}$ & $\begin{array}{l}\text { Corrigir: } \\
\text { Bordas, pontas e cantos dentro da área } \\
\text { de acesso devem estar cobertas com } \\
\text { material acolchoado ou não devem } \\
\text { existir dentro da área de acesso }\end{array}$ & $\begin{array}{l}\text { Restrições mais severas com relação à área de acesso da } \\
\text { criança são necessárias, pois o conduzido pode não respeitar } \\
\text { a posição padrão para a condução, se movendo para os lados } \\
\text { e tentando acessar o que estiver ao alcance das mãos. }\end{array}$ \\
\hline $\begin{array}{l}6.1 .4 \text { Partes } \\
\text { pequenas }\end{array}$ & $\begin{array}{l}\text { Incluir: } \\
\text { Englobar também partes pequenas que } \\
\text { se dividem em partes menores }\end{array}$ & $\begin{array}{l}\text { Partes móveis podem conter outras partes pequenas dentro de } \\
\text { si, que podem se dividir em componentes menores. }\end{array}$ \\
\hline
\end{tabular}




\begin{tabular}{|c|c|c|}
\hline 6.1.6 Cordões e tiras & $\begin{array}{l}\text { Incluir: } \\
\text { Não colocar amarrações de cordões e } \\
\text { tiras em local acessível ao bebê }\end{array}$ & $\begin{array}{l}\text { Crianças são curiosas e, ao encontrar cordões ou tiras, } \\
\text { principalmente quando em cores chamativas, se sentirão } \\
\text { estimuladas a interagir. }\end{array}$ \\
\hline $\begin{array}{l}\text { 6.1.8 Fixação das } \\
\text { partes de tecido } \\
\text { com finalidade de } \\
\text { retenção da criança. }\end{array}$ & $\begin{array}{l}\text { Corrigir: } \\
\text { Utilizar simulacro de criança mais } \\
\text { próximo do real em substituição à } \\
\text { esfera de ensaio }\end{array}$ & $\begin{array}{l}\text { Simular as condições de deslocamento do bebê no carrinho a } \\
\text { partir da inclinação e, se possível, seu movimento ou posição } \\
\text { que possa vir a ficar quando retido. Isso trará resultados mais } \\
\text { fidedignos aos pretendidos. }\end{array}$ \\
\hline $\begin{array}{l}\text { 6.2.1. Altura mínima } \\
\text { interna do cesto } \\
\text { para bebês }\end{array}$ & $\begin{array}{l}\text { Incluir: } \\
\text { Considerar modos de uso fora do } \\
\text { previsto pelo fabricante, como o } \\
\text { condutor ser outra criança }\end{array}$ & $\begin{array}{l}\text { Mesmo que as partes sejam projetadas para um uso } \\
\text { específico, o uso indevido deve ser considerado e se possível } \\
\text { inviabilizado. }\end{array}$ \\
\hline $\begin{array}{l}\text { 6.2.2.2 Medição do } \\
\text { ângulo do encosto }\end{array}$ & $\begin{array}{l}\text { Incluir: } \\
\text { Adequação ao corpo do bebê }\end{array}$ & $\begin{array}{l}\text { A possibilidade de ajustar as inclinações para adequar à } \\
\text { posição de sentar é uma opção viável para acompanhar o } \\
\text { crescimento da criança. A medição portanto, deverá possuir } \\
\text { valor mínimo e máximo. }\end{array}$ \\
\hline $\begin{array}{l}6.3 .2 \text { Instalação do } \\
\text { cesto para bebês e } \\
\text { da unidade de } \\
\text { assento no chassi }\end{array}$ & $\begin{array}{l}\text { Incluir: } \\
\text { Exigência de feedback sonoro ou visual } \\
\text { de que a ação foi executada com } \\
\text { sucesso }\end{array}$ & $\begin{array}{l}\text { O usuário realiza ações esperando alguma confirmação de } \\
\text { que obteve êxito. Se isso não ocorre, ele pode interpretar que } \\
\text { não completou a ação; ou que a completou mesmo que não a } \\
\text { tenha concluído, podendo induzi-lo a acidentes. }\end{array}$ \\
\hline 7 Ensaio & $\begin{array}{l}\text { Incluir: } \\
\text { Realização de testes com vários } \\
\text { elementos comuns do dia-a-dia } \\
\text { dispostos nos compartimentos, com } \\
\text { peso estipulado pelo fabricante }\end{array}$ & $\begin{array}{l}\text { No dia-a-dia, o usuário carrega consigo itens de uso comum } \\
\text { do bebê como bolsas com fraldas, mamadeiras e brinquedos. } \\
\text { Estes itens representam uma situação mais próxima do real, } \\
\text { devendo ser usados nos testes com bagagem. }\end{array}$ \\
\hline 9 Alça & $\begin{array}{l}\text { Incluir: } \\
\text { Teste de pegas e manejos para áreas } \\
\text { de contato com a mão }\end{array}$ & $\begin{array}{l}\text { Verificar o conforto das alças, áreas de contato, controle de } \\
\text { direcionamento da carga e da força necessária ao uso em } \\
\text { condições mais severas. O Teste de Erick pode fornecer } \\
\text { indícios de pontos de contato que podem machucar o usuário. }\end{array}$ \\
\hline $\begin{array}{l}\text { 10.1 Dispositivos de } \\
\text { estacionamento e } \\
\text { frenagem / } \\
\text { Requisitos }\end{array}$ & $\begin{array}{l}\text { Incluir: } \\
\text { Exigência de uso de cores de destaque } \\
\text { para identificar alavancas e botões de } \\
\text { acionamento de freio }\end{array}$ & $\begin{array}{l}\text { Em caso de emergência é essencial encontrar, identificar e } \\
\text { compreender o funcionamento de acionamentos mecânicos } \\
\text { disponíveis no carrinho, tornando sua ação a mais rápida } \\
\text { possível. }\end{array}$ \\
\hline $\begin{array}{l}10.1 \text { Dispositivos de } \\
\text { estacionamento e } \\
\text { frenagem / } \\
\text { Requisitos }\end{array}$ & $\begin{array}{l}\text { Incluir: } \\
\text { Indicação visual do modo de } \\
\text { acionamento }\end{array}$ & $\begin{array}{l}\text { Para o usuário, deve ficar claro qual o movimento que ele deve } \\
\text { realizar: empurrar ou puxar, girar para a esquerda ou para a } \\
\text { direita, assim como se o acionamento funciona em conjunto } \\
\text { com outro. }\end{array}$ \\
\hline $\begin{array}{l}11.1 \text { Trava de } \\
\text { segurança / } \\
\text { Requisitos }\end{array}$ & $\begin{array}{l}\text { Incluir: } \\
\text { Definir valores toleráveis de aplicação } \\
\text { de força no manejo das travas }\end{array}$ & $\begin{array}{l}\text { Regulamentar a força aplicada no acionamento das travas, } \\
\text { para não causar lesões nas mãos do condutor, e evitar que } \\
\text { este tenha dúvidas sobre a direção e o modo de acionamento; } \\
\text { além de permitir o uso por pessoas com limitações, como } \\
\text { idosos. }\end{array}$ \\
\hline $\begin{array}{l}11.1 \text { Trava de } \\
\text { segurança / } \\
\text { Requisitos }\end{array}$ & $\begin{array}{l}\text { Incluir: } \\
\text { Restrições de movimento no } \\
\text { acionamento para mudança de } \\
\text { configuração das travas }\end{array}$ & $\begin{array}{l}\text { Garantir que o travamento seja realizado sem impedimento por } \\
\text { outras partes do carrinho, como por exemplo, a interferência } \\
\text { do cinto de segurança em engrenagens e partes móveis. }\end{array}$ \\
\hline $\begin{array}{l}4.5 \text { Manejo do } \\
\text { carrinho }\end{array}$ & $\begin{array}{l}\text { Incluir: } \\
\text { Definição de zona livre para acesso a } \\
\text { compartimentos, assim como preservar } \\
\text { o tamanho desses compartimentos }\end{array}$ & $\begin{array}{l}\text { Ao modificar configurações possíveis do carrinho, } \\
\text { compartimentos e bolsos devem permanecer acessíveis, sem } \\
\text { inviabilizar o uso em qualquer configuração. A mudança } \\
\text { também não deve comprimir objetos armazenados. }\end{array}$ \\
\hline
\end{tabular}

Tabela 9. Ajustes nos ensaios da norma vigente (produção dos autores).

Houve tópicos presentes na norma onde não foram sugeridas modificações e implementações, devido a não correlação com a experiência do usuário, além da natureza dos ensaios e do objetivo de cada teste estarem fora do escopo deste trabalho. Isso não inviabiliza sua realização nem invalida seus resultados, mantendo-se a importância e o valor agregado por eles na análise total do produto. 


\section{Conclusões}

Este artigo visa contribuir com o campo das análises dos produtos de consumo, no recorte dos carrinhos para criança, produto regulamentado pelo Inmetro com foco na segurança. O estudo ampliou o enfoque da missão do Inmetro na avaliação de produtos, abrangendo as disciplinas da Ergonomia, da Usabilidade e da Acessibilidade. Dentre os resultados alcançados, destacam-se a revisão de diretrizes dos quatro campos estudados; as heurísticas elaboradas a partir deste levante e revisadas na aplicação de um teste piloto; as sugestões de correção para o modelo de carrinho com defeito; a aplicação de alguns métodos e práticas de avaliação, como o Teste de Erick (OLIVEIRA, 2010); e finalmente, as inferências na norma, já que atualmente ela não contém qualquer direcionamento à análise dessas quatro disciplinas.

\subsection{Obstáculos da pesquisa}

Em face do problema apresentado pelo Inmetro, a primeira grande dificuldade foi decidir por um protocolo de teste a ser aplicado para avaliar o produto, já que não havia na norma NBR 14389:2010 menção de tópico ou diretriz de ergonomia. Outras normas estudadas não traziam qualquer conteúdo específico para avaliação, o que conduziu a equipe a novas discussões e a novos direcionamentos: mais importante que realizar os testes de ergonomia no carrinho, seria primeiro construir o conjunto de crivos que determina qual seria essa qualidade ergonômica pretendida em tais produtos.

Outro obstáculo foi encontrado durante as etapas iniciais de revisão, quando era construída uma string de busca: esta seria uma revisão sistemática, com critérios de inclusão e de revisão muito bem definidos e rigorosos, além da revisão por pares dos artigos levantados, que seria executada pelos dois membros pesquisadores. Contudo, ao se unir os quatro campos de conhecimento (termos relacionados à ergonomia, usabilidade, acessibilidade e ux) aos carrinhos numa única string de busca, não surgia nos resultados número significativo e/ou diretamente ligado aos tópicos pesquisados, exceto por alguns já utilizados na atual revisão.

Também não há informações nos documentos sobre referências antropométricas utilizadas para a definição do padrão dos testes, restando à equipe de pesquisa uma análise que respeitasse os valores estabelecidos. Finalmente, um único carrinho não é capaz de gerar dados de validação para um protocolo de testes: serão necessários mais modelos desta e de outras marcas, a fim de aumentar o potencial comparativo dos resultados.

\subsection{Recomendações para futuros trabalhos}

A validação do protocolo através de sua aplicação em outros carrinhos para criança a fim de gerar comparações entre eles, é a sugestão para o primeiro trabalho futuro, consequente deste estudo. Os resultados da aplicação piloto deverão orientar os testes com usuários. Após aplicação e validação dos testes, o fabricante do carrinho utilizado no teste piloto poderá fazer os aprimoramentos em seu produto, bem como outros fabricantes deste mesmo produto. Uma vez validado o Protocolo de Testes em sua versão final, o referido Protocolo pode ser apresentado como proposta de inserção aos ensaios da norma ABNT NBR 14389 (ABNT, 2010) que ampliará sua abrangência. Um modelo de carrinho para criança que além cumprir os requisitos de segurança apresentar aspectos ergonômicos, de usabilidade e acessibilidade validados será um produto com maior grau de aceitação pelo usuário infantil e para o seu condutor, e poderá ser objeto de uma patente de modelo de utilidade ocasionando uma vantagem competitiva ao seu titular. 


\section{Referências Bibliográficas}

ABNT NBR 14389: Segurança de carrinhos para crianças. Associação Brasileira de Normas Técnicas, Rio de Janeiro, 2010.

ABNT NBR 14400: Veículos rodoviários automotores - Dispositivos de retenção para crianças Requisitos de segurança. Associação Brasileira de Normas Técnicas, Rio de Janeiro, 2009.

ABNT NBR ISO/IEC 17025: Requisitos gerais para a competência de laboratórios de ensaio e calibração. Associação Brasileira de Normas Técnicas, Rio de Janeiro, 2017.

ABNT NBR NM 300:1-3: Segurança de brinquedos. Associação Brasileira de Normas Técnicas, Rio de Janeiro, 2004.

BRASIL. Lei $\mathbf{N}^{0}$ 9.933, de 20 de Dezembro de 1999. Dispõe sobre as competências do Conmetro e do Inmetro, institui a Taxa de Serviços Metrológicos, e dá outras providências. DOU de 21.12.1999.

BRASIL. Lei $\mathbf{N}^{\mathbf{0}} \mathbf{1 2 . 5 4 5}$, de 14 de Dezembro de 2011. Dispõe sobre o Fundo de Financiamento à Exportação (FFEX) e dá outras providências. DOU 15.12.2011.

BS EN 1888: Child Care Articles - Wheeled Child Conveyances - Safety Requirements and Test Methods. British Standards Institution (BSI), 2003.

CUSHMAN, W. H.; ROSENBERG, D. J.. Human Factors in Product Design. Amsterdam: Elsevier, 1991. FERNANDES, J. D.; MACHADO, M. C. R.; OLIVEIRA Z. N. P.. Prevenção e cuidados da pele da criança e do recém-nascido. Anais Brasileiros de Dermatologia, v. 86, n. 1, p. 102-10, 2011.

GOMES FILHO, J. Gestalt do objeto: sistema de leitura visual da forma / João Gomes Filho. -8 ed. rev. e ampl. - São Paulo: Escrituras Editora, 2008.

INMETRO. Acesso à Informação. Disponível em: http://www4.inmetro.gov.br/acesso-ainformacao/institucional. Acesso em: 10 ago. 2020.

INMETRO. Acesso à Informação. Disponível em: http://www4.inmetro.gov.br/acesso-ainformacao/institucional/avaliação. Acesso em: 19 ago. 2020a.

INMETRO. Portaria Inmetro no 351 de 06/07/2012. Requisitos de Avaliação da Conformidade para Carrinhos para Crianças. Disponível em: http://www4.inmetro.gov.br/acesso-ainformacao/institucional/avaliação. Acesso em: 19 ago. $2020 \mathrm{~b}$.

INMETRO. Portaria Inmetro no 315 de 19/06/2012. Regulamento Técnico da Qualidade para Carrinhos para Crianças. Disponível em: http://www4.inmetro.gov.br/acesso-ainformacao/institucional/avaliação. Acesso em: 19 ago. 2020c.

ISO. ISO 9241-20: Ergonomics of human-system interaction - Part 20: Accessibility guidelines for information/communication technology (ICT) equipment and services. ISO, 2006.

ISO. ISO 9241-171: Ergonomics of human-system interaction - Part 171: Guidance on software accessibility. ISO, 2008. 
ISO. ISO/IEC Guide 71: Guidelines for standards developers to address the needs of older persons and persons with disabilities. ISO, 2001.

KANNENGIESSER, U.; GERO, J. S.. A Process Framework of Affordances in Design. Design Issues, v. 28, n. 1, p. $50-62,2012$.

LERNER, N. D.; HUEY, R. W.; MEIERS, C.. Human Factors Considerations for High Chair and Stroller Child Restraints. Proceedings of the Human Factors and Ergonomics Society 46th Annual Meeting, p. 710-714, 2002.

MARCONI, M. A.; LAKATOS, E. M.. Metodologia Científica. 7 ed. São Paulo: Atlas, 2017.

MARTIN, B.; HANINGTON, B.. Universal Methods of Design: 100 Ways to Research Complex Problems, Develop Innovative Ideas, and Design Effective Solutions. Massachusetts: Rockport Publishers, 2012.

NIELSEN, Jakob. 10 Heuristics for User Interface Design. California: NN/G, 1994. Disponível em: https:/www.nngroup.com/articles/ten-usability-heuristics/. Acesso em: 14 ago. 2020.

NIELSEN, Jakob. Usability 101: Introduction to Usability. California: NN/G, 2012. Disponível em: https://www.nngroup.com/articles/usability-101-introduction-to-usability/. Acesso em: 7 ago. 2020.

NIELSEN, Jakob. Usability Engineering. 1 ed. Boston: Academic Press, 1993.

NORMAN, D.; NIELSEN, J.. The Definition of User Experience (UX). California: NN/G, 2020.

Disponível em: https://www.nngroup.com/articles/definition-user-experience/. Acesso em: 7 ago. 2020.

OLIVEIRA, N. M.. Pegas e Manejos: Ergonomia \& Design. UFCG CCT, Curso de Design, 2010.

Disponível em: https://natamorais.files.wordpress.com/2010/10/manejos2014.pdf . Acesso em: 9 ago. 2020.

PERNICE, Kara. Design Systems and Their Benefits. NN/G, 2018. Disponível em: https://www.youtube.com/watch?v=3 TpiNrZlzt4. Acesso em: 14 ago. 2020.

RICE, V.; LUEDER, R.. Designing products for children / Lueder R. and Rice V. J. B. (Eds.). Ergonomics for children - Designing products and places for toddlers to teens, p. 399-476. Boca Raton: Taylor \& Francis, 2008.

SEHAT, A. R.; NIRMAL, U.. State of the art baby strollers: Design review and the innovations of an ergonomic baby stroller. Cogent Engineering, v. 4, n. 1, 2017.

SENGÖLGE, M.; VINCENTEN, J.. Child Safety Product Guide: potentially dangerous products. Birmingham: European Child Safety Alliance - EuroSafe, 2013.

SIDI. Guia para o Desenvolvimento de Aplicações Móveis Acessíveis. Disponível em: http://www.sidi.org.br/guiadeacessibilidade/index.html\#requisitos. Acesso em: 14 ago. 2020.

EUROPEAN COMMISSION. Sistema de análise de riscos em produtos de consumo, renomeado posteriormente para Safety Gate. RAPEX, 2019. Disponível em:

https://ec.europa.eu/consumers/consumers_safety/safety_products/rapex/alerts/repository/content/p ages/rapex/index_en.htm. Acesso em: 16 ago. 2019. 
U.S. CONSUMER PRODUCTS SAFETY COMMISSION. Consumer product safety alert from the U.S. Consumer Product Safety Commission (Vol. 33-35). Minnesota: The Comission, 1997.

W3C. Web Content Accessibility Guidelines (WCAG) 2.1. Disponível em: https://www.w3.org/TR/WCAG21/. Acesso em: 14 ago. 2020.

ZUNJIC, Aleksandar. Ergonomics for newborns - Certain implications and recommendations for parents and designers. IETI Transactions on Ergonomics and Safety, v. 1, n. 2, p. 1-10, 2017. 